REFERENCES

Court, S. D. M., and Knox, E. G. (1959). Brit. med. J., 2, 408. Creery, R. D. G. (1955). Ibid., 2, 178

Eliot, E., and Corscaden, J. A. (1911). Ann. Surg., 53, 169

Fitzwilliams, D. C. L. (1908). Lancet, 1, 628, 709.

Gardner, P. S. (1961). Brit. med. J., 2, 495.

- McGregor, C. B., and Dick, K. (1960), Ibid, 1, 91.

Wright, A. E., and Hale, J. H. (1961). Ibid., 2, 424.

MacMahon, B. (1955). Amer. J. hum. Genet., 7, 430.

Ministry of Health (1959). Public Health and Medical Subjects Report No. 99. H.M.S.O., London

Mooro, A. W. (1924). Brit. med. J., 1, 319.

Ross, J. G., and Potter, C. W. (1961). Lancet, 1, 81.

Sheh Ya Hsiung, Ma An Ch'uan, Yang Yung-K'ang, and Sun Chien-Min (1957). Chin. med. J., 75, 409.

Smith, I. McD. (1960). Brit. med. J., 1, 551.

Steyn, J., and Kyle, J. (1961). Ibid., 1, 1730.

Zachary, R. B., and Potter, C. W. (1961). Proc. roy. Soc. Med., 54, 1018 .

\section{VIRUS INFECTION AND INTUSSUSCEPTION IN CHILDHOOD}

BY

\section{P. S. GARDNER, M.D., Dip.Bact.}

E. G. KNOX, M.D., M.R.C.P.

S. D. M. COURT, M.D., F.R.C.P.

AND

C. A. GREEN, M.D., Ph.D., D.P.H.

From the Departments of Bacteriology and Child Health, United Hospitals and King's College, Newcastle upon Tyne

The association of adenovirus infection and intussusception has been suspected since the work of Gardner (1961) and Ross and Potter (1961), but satisfactory proof of a causal role has proved difficult. Knox et al. (1962) discussed the interrelations of various factors, including infection, in the aetiology of intussusception and showed that a number of determinants exist, but contended that no single cause was always followed by the disease or was always present before the disease. In addition to the existence of several causal factors which could vary in importance in different communities, they pointed out the difficulties of ascertaining the prevalence of adenovirus in a general population of the same age, especially the selection of a control group of normal children. Children admitted to hospital for purposes other than the treatment of intussusception can scarcely be regarded as normal, since adenoviruses are known to play a part in a variety of diseases of the respiratory and alimentary tracts.

In these conditions it has been shown that adenovirus may be excreted in large quantity in the stool (Kjellen et al., 1957a, 1957b ; Gardner et al., 1960 ; Duncan and Hutchinson, 1961), but there is conflicting evidence as to their role in diarrhoea. Ramos-Alvarez and Sabin (1958) and Sommerville (1958), in two surveys of diarrhoea, found no increase in the incidence of adenovirus, but this is in contrast to other workers (Gardner et al., 1960 ; Kjellén et al., 1957a, 1957b ; Kendall et al., 1957 ; Duncan and Hutchinson, 1961), who have found the epidemic types of adenovirus associated with diarrhoea, often, but by no means invariably, in conjunction with respiratory illness. All workers agree that when an adenovirus causes respiratory illness it may be excreted in the stool. Residential nurseries where infants and pre-school children can readily be studied are unsuitable, for if an adenovirus infection is present in such a closed community all will be infected and many will excrete adenovirus for many months (Gardner et al., 1961). Child welfare centres are probably capable of supplying the best source of material for comparison but have the disadvantage that it is unjustified to obtain repeated samples of venous blood from normal children.

For these reasons, and because it is difficult to rely upon any single source of material as an indication of population prevalence, we felt it essential for a conclusive demonstration of the role of adenovirus the aetiology of intussusception that a variety of controls should be used.

To substantiate the view that intussusception was a systemic infection it is necessary to show evidence of a generalized infection besides the faecal excretion, and so, whenever possible, both paired sera and mesenteric lymph nodes removed at operation were studied for evidence of virus infection.

If adenoviruses are causally associated with intussusception other viruses multiplying in the alimentary tract might be associated with intussusception too. We hope to show that this is true.

The main objective of this study was to measure the incidence of virus infections in children with intussusception and their timing in relation to the onset, and to compare the results with those obtained from a variety of control groups described below.

\section{Materials and Methods}

Selection of Cases of Intussusception.-All affected children admitted to the wards of the Royal Victoria Infirmary from June, 1961, to June, 1962, were accepted for the investigation. In all, 38 cases were obtained.

Selection of Control Cases.-These were divided into three groups. (1) Diarrhoeal group: All children in the age-group of 3 to 12 months with diarrhoea admitted to Walkergate Hospital over the same period of time were used. This provided a total of 62 cases. (2) Bronchiolitis and pneumonia group: During the period of study an investigation into the role of viruses in acute bronchiolitis and in pneumonia was running concurrently and it was decided to use cases of an appropriate age for an additional control. (3) Normal children : Eight children were selected from the teaching hospital child welfare centre and samples of faeces collected for investigation at regular intervals during their first year of life. Two members of the staff whose wives had babies during the period of study allowed us to use their infants as additional controls.

Techniques for Virus Isolation.-Faeces from all cases of intussusception and the three sets of controls were examined on HeLa cells and monkey-kidney-tissue cultures. The majority of these specimens were examined on Hep 2 cells. Throat swabs were examined in an identical manner. The methods of isolation and identification of herpes simplex virus and adenovirus have been adequately described in previous publications (Munro-Ashman et al., 1958; Gardner, 1961), and the methods in this study were similar to these. If an enterovirus was suspected the appropriate antisera were used in a neutralization test. In 21 of the 38 children with intussusception a surgeon removed a mesenteric lymph node at operation for attempted virus isolation. 
These were sent to the laboratory as soon as possible. For the first six months of the investigation small fragments of the gland were embedded in a plasma clot and then grown in Hanks's basic salt solution containing $0.5 \%$ lactalbumin hydrolysate, $20 \%$ calf serum antibiotics, and sodium bicarbonate. Part of the gland was ground and the supernatant from a suspension was inoculated into the tissue culture tubes. For the second six months exactly the same technique as before was carried out, but in addition further fragments were suspended in growth medium and no attempt was made to make them adhere to the glass; other fragments were stuck to the glass dry by incubating them in a dry tissue culture tube in an incubator at $37^{\circ} \mathrm{C}$. for half an hour. Growth medium was then added. Thus each lymph node was eventually examined using these four methods.

Serological Techniques.-A complement-fixation test similar to that used by Munro-Ashman et al. (1958) was performed on all sera if present in sufficient quantity. If the results were negative, or if the quantity of serum was very small, an overnight complement-fixation test based on the original method of Fulton and Dumbell (1949) was used; this also increased the sensitivity of the test. The complement-fixation test for herpes simplex was also of the latter type.

\section{Results}

From 37 of the 38 children with intussusception admitted during the year at least one specimen of faeces was obtained, but usually more. Similarly the 62 children with diarrhoea and the 38 with pneumonia and bronchiolitis had a similar number of faeces examined. The 10 normal children had stools examined at monthly intervals ; this work is continuing, but so far an average of five stools per child have been examined.

In our experience when an adenovirus type was present in more than one site-for example, throat swab and faeces or faeces and mesenteric gland-it has so far always been of the same type.

Isolation of Virus from Stools.-Table I summarizes the examination of the stools from the cases of intussusception and the three control groups. It also illustrates the various agents found.

TABLE I.-Isolation of Viruses from Faeces of Intussusceptions and Controls

\begin{tabular}{|c|c|c|c|c|c|}
\hline $\begin{array}{c}\text { Type } \\
\text { of Case }\end{array}$ & $\begin{array}{l}\text { Total } \\
\text { No. }\end{array}$ & $\begin{array}{c}\text { No. } \\
\text { Negative }\end{array}$ & $\begin{array}{l}\text { No. } \\
\text { with } \\
\text { Adeno- } \\
\text { virus }\end{array}$ & $\begin{array}{l}\text { No. } \\
\text { with } \\
\text { Herpes } \\
\text { Simplex }\end{array}$ & $\begin{array}{l}\text { No. } \\
\text { with } \\
\text { Polio- } \\
\text { virus }\end{array}$ \\
\hline $\begin{array}{l}\text { Intussusception } \\
\text { Diarrhoea control group ... } \\
\text { Bronchinlitis control group } \\
10 \text { normal children }\end{array}$ & $\begin{array}{l}37 \\
62 \\
38 \\
56\end{array}$ & $\begin{array}{l}17 \\
60 \\
37 \\
54\end{array}$ & $\begin{array}{r}17 \\
2 \\
1 \\
2\end{array}$ & $\begin{array}{l}2 \\
0 \\
0 \\
0\end{array}$ & $\begin{array}{l}1 \\
0 \\
0 \\
0\end{array}$ \\
\hline
\end{tabular}

In addition one child with an intussusception was found to be excreting Shigella sonnei. These results were obtained using HeLa or Hep 2 cells only.

Isolation of Virus from Throat Swab.-From the 38 cases of intussusception 26 throat swabs were received, five of which were positive. In three cases the virus isolated from the throat swab was of the same type as that isolated in the stool, in one child no faeces were obtained, and in one no virus was isolated from a single specimen of faeces.

Isolation of Virus from Mesenteric Lymph Nodes.Twenty-one mesenteric lymph nodes were examined, seven of which yielded an adenovirus. It was impossible to obtain controls for mesenteric lymph nodes, as laparotomies in this age group for reasons other than intussusception are extremely rare. A total of 17. children with intussusception had adenovirus in their faeces, and from eleven of these mesenteric lymph nodes were sent. From six of these adenovirus was isolated.

Distribution of Virus Types.-As previously observed (Gardner, 1961), the majority of adenoviruses isolated in intussusception were of the non-epidemic types-that is, types $1,2,5$, and 6 . In this present study eight were type 1 , six were type 2 , three were type 5 , and one was type 6. No types 3,4 , or 7 were found, but two strains could not be typed. The two adenoviruses isolated from the diarrhoeal controls were type 5 and type 4 , the one isolated from the bronchiolitis and pneumonia controls was a type 3 , while the two from normal children were types 1 and 5 .

Serological Evidence of Virus Infection.-A total of 35 pairs of sera were examined; 18 patients had evidence of a recent infection with adenovirus while four had evidence of recent infection with herpes simplex virus. Only those sera which gave evidence of a recent infection are recorded as positive. If the results of all our findings in the case of intussusception are summarized we find that there is evidence of infection with adenovirus in $63 \%$ and with herpes simplex in $10.5 \%$. If the two cases, one excreting Shigella sonnei and the other excreting poliovirus, are included a total of $80 \%$ of cases of intussusception might be associated with an infective aetiology. Table II compares adenovirus isolations from the stools of the children with intussusceptions, diarrhoea, and bronchiolitis and pneumonia, and from the normal children.

\begin{tabular}{c|c|c|c} 
TABLE II.-Proportions of Faecal Adenovirus Isolation in \\
Intussusceptions and Controls
\end{tabular}

Clinical Variation in Relation to Virus Isolation

With the culture differences in mind we looked again at children with and without evidence of virus infection and also at the several types of virus infection to see whether any clinical differentiation was possible. We found first a significant age difference: 12 of the 20 patients from whom adenovirus was isolated were under 1 year of age, compared with 13 of the 15 from whom adenovirus was not isolated. Adenovirus seems less likely to be isolated in younger affected children than in older ones, but it is difficult to say whether this represents a technical artifact or a predominance of other aetiological factors in the younger children.

The clinical course of the intussusception in the child from whom vaccine strains of poliovirus were recovered was entirely typical. The four children with herpes infection likewise showed no atypical clinical features, but one recurred after three weeks, a circumstance which accords with the natural history of herpes simplex infections in general and so tends to confirm its causal role in this case. It should be mentioned here that the case previously reported (Gardner, 1961) from which herpes simplex virus was isolated was not the same case as the one reported here and that this, too, was a recurrent intussusception. Another of the children from whom herpes simplex virus was isolated later presented with fits and after a further interval with 
other abdominal symptoms which did not, however, seem to be due to intussusception. No other herpetic lesions were recorded in any of the children with herpes, but special efforts to detect and record them were not made.

Among the children from whom no virus was isolated most were quite typical in onset and course, although one child had the unusual combination of two separate simultaneous intussusceptions, one ileo-ileal and the other colo-colic.

Yet, taking the groups with and without evidence of virus infection, no clear clinical differences could be found between them. Neither the symptoms before the onset of the intussusception, nor the presence of enlarged lymph nodes, nor the course of the illness afforded any means of differentiation. Meckel's diverticula were found in two children-one where adenovirus was recovered and one where virus was not recovered; in neither case was the diverticulum involved in the intussusception.

\section{Discussion}

Viruses in intussusception might be causal or their presence merely coincidental. We felt that if we could demonstrate that adenovirus was causing a generalized infection and if there was a significant difference from carefully chosen control groups the belief that they play a causal part would stand on firmer ground.

In our cases we have found not only evidence of heavy faecal excretion of adenovirus but in a substantial proportion the same adenovirus was present in the upper respiratory tract and in the lymph nodes. We know that infants are a notoriously bad group from the point of view of producing demonstrable antibody response, but nevertheless we found evidence of antibody response in many. Moreover, at operation many large fleshy lymph nodes were found. We consider that this combination affords convincing evidence of an active adenovirus infection in a majority of affected children and that comparison with the low frequency in controls establishes that the association is causal.

However, in the complex aetiology of intussusception the virus factor, although of great importance, is just one among a number of contributory causes (Knox et al., 1962).

The next question is, that although adenovirus appears to be associated with a high proportion of intussusceptions, are any other viruses involved? Here the answer is less definite. We have evidence that in a small number of cases herpes simplex virus may play a part. This part may be larger than our isolations suggest, as herpes simplex virus is most delicate and we took no special precautions in the collection of specimens. Again, in the main, HeLa cells were used, and this is probably not the best way of isolating herpes simplex from fresh cases. Finally, some cases may have been missed serologically because of the poor responses in this age-group. Nevertheless, an interesting fact has emerged. If we include the case reported by Gardner (1961) from which herpes simplex virus was isolated and the one in our present series we find that two cases of recurrent intussusception were both excreting herpes simplex virus. These were the only two children with recurrent intussusception on whom virus studies have been carried out, and we feel that recurrences are uncommon enough to suggest a specific association. It may be that the primary herpetic infection has been alimentary and associated with the first intussusception and when a recrudescence of the herpes infection took place it was at the primary site and predisposed to a second intussusception. We failed to isolate herpes simplex from any of the mesenteric lymph nodes, and this may have been due to our technique. We were looking for adenovirus in the lymph nodes and therefore kept them growing for 28 days, but this may not be the optimum way of isolating herpes simplex virus from lymphoid tissue.

Undue prominence should not be given to our single patient who was excreting poliovirus types 2 and 3 ; his intussusception occurred five days after being fed a live poliovirus vaccine. On theoretical gruunds if adenovirus infection is capable of predisposing to intussusception enteroviruses multiplying presumably in similar alimentary sites could act likewise. It is important to see if further cases occur, but as part of the Medical Research Council live puliuvirus vaccine trial 35 Newcastle children of 6-12 munths were fed with live vaccine and none developed intussusception (Hale et al., 1961). In countries with a high standard of living it is generally accepted that enterovirus infection is now comparatively rare in the first year of life, when the child is mainly confined to pram or cot and its opportunities for exposure are limited. This may be why we have not so far seen enteroviruses in many intussusceptions. Possibly after a certain stage of growth, reached at about 2 years of age. the gut is wide enough to withstaind the effects of partial obstruction and fluid loading, and virus infection is no longer a critical factor.

Our isolated case with Shigella sonnei in the stools is probably of no significance, but one must recall that occasionally typhoid fever has been associated with intussusception.

Finally, except in recurrent intussusception there was no evidence that isolation of virus lends itself to a valid clinical subclassification of intussusception.

\section{Summary}

Virus and bacteriological investigations in 38 children with intussusception are described. Infective agents were found to be associated with $80 \%$ of cases. The figure for faecal isolation of adenovirus, $46 \%$, was highly significant when compared with a number of control groups. Isolation of the same viruses from throat swabs and lymph nodes, together with antibudy responses, indicates that these isolations represent active and probably recent systemic infeetion. The main agents isolated were adenoviruses types 1, 2, 5, and 6 and herpes simplex virus. The part played by each group of viruses isolated is discussed and the conclusion reached that viruses, particularly adenoviruses, play a causal part in the aetiology of intussusception.

We thank Miss Joyce McQuillin for her technical assistance. Our thanks are also due to Dr. E. G. Brewis for faeces from children with diarrhoea, to Dr. R. C. M. Pearson and Dr. Mary Taylor for supplying specimens from normal children, to Dr. F. Miller for permission to investigate cases under his care and for his help in organizing this study, and to a number of surgeons who removed mesenteric lymph nodes. We are indebted to the Standards Laboratory, Colindale, for supplying herpes simplex antigen and antiserum. 
REFERENCES

Duncan, I. B. R., and Hutchinson, J. G. P. (1961). Lancet, 1, 530

Fulton, F., and Dumbell, K. R. (1949). J. gen. Microbiol., 3, 97. Gardner, P. S. (1961). Brit. med. J., 2, 495

McGregor, C. B., and Dick, K. (1960). Ibid., 1, 91.

Hale, J. H., Lee, L. H., and Gardner, P. S. (1961). Ibid., 2, 728 Kendall, E. J. C., Riddle, R. W., Tuck, H. A., Rodan, K. S., Andrews, B. E., and McDonald, J. C. (1957). Ibid., 2, 131

Kjellén, L., Sterner, G., and Svedmyr, A. (1957a). Acta paediat. (Uppsala), 46, 164.

Zetterberg, B., and Svedmyr, A. (1957b). Ibid., 46, 561.

Knox, E. G., Court, S. D. M., and Gardner, P. S. (1962). Brit. med. J., 2, 692

Munro-Ashman, D., Gardner, P. S., Taylor, C. E. D., and McDonald, J. C. (1958). Lancet, 2, 121.

Ramos-Alvarez, M., and Sabin, A. B. (1958). J. Amer. med. Ass., 167, 147.

Ross, J.' G., and Potter, C. W. (1961). Lancet, 1, 81.

Sommerville, R. G. (1958). Ibid., 2, 1347.

\section{VIRUSES IN LYMPH NODES OF CHILDREN WITH MESENTERIC ADENITIS AND INTUSSUSCEPTION}

BY

THOMAS M. BELL, B.Sc.

Lecturer in Bacteriology

AND

JOHN H. STEYN, M.B., Ch.B., F.R.C.S. Surgical Registrar

From the Departments of Bacteriology and Surgery, University of Aberdeen, and the Royal Aberdeen Hospital for Sick Children

Since the original isolation of members of the adenovirus group from hypertrophied tonsils and adenoids (Rowe et al., 1953), and the discovery that infection with this group may give rise to localized lymphadenopathy (Bell, 1957), several workers have tried to find an association between adenovirus infection and the clinical condition of non-specific mesenteric lymphadenitis (Aird, 1945) ; Kjellén (1955) and Kjellén et al. (1957) reported the isolation of six strains of adenovirus from 113 such cases and Van der Veen (1958) two isolations from an unspecified number of cases.

Ross and Potter (1961) have isolated adenovirus from 11 out of 16 cases of acute idiopathic intussusception. Gardner (1961) examined the faeces from 10 cases of intusssusception and isolated adenovirus from six and herpes simplex virus from one.

In Aberdeen we began to examine lymph nodes removed at operation from cases of non-specific mesenteric adenitis in November, 1959, and included cases of acute idiopathic intussusception from January, 1960. Our aim was to determine whether virus could be isolated from such material and whether the findings differed in any way from those in a control group of children not suffering from these conditions. In a preliminary communication (Steyn and Bell, 1961) we reported the isolation of adenovirus from 10 out of 11 cases of intussusception, from 11 out of 22 cases of mesenteric adenitis, and from 1 out of 23 controls.

This paper deals in more detail with the results of the investigation between November, 1959, and February, 1961.

\section{Methods and Materials}

Three groups of cases were studied: (1) acute idiopathic intussusception, 17 cases; (2) non-specific mesenteric adenitis (identified at operation), 32 cases; and (3) "control" group, 50 cases. The controls were patients submitted to laparotomy for a variety of reasons, the majority being early cases of acute appendicitis subsequently confirmed by histological examination but also including lesions such as intestinal obstruction, swallowed foreign body, and threadworm infestation. Full details are given in Table I.

Table 1.-List of Control Cases

\begin{tabular}{|c|c|c|c|}
\hline Disease & No. of Cases & Diseas : & No. of Cases \\
\hline Appendicitis & 32 & Spina bifida manifesta & \\
\hline Ingested foreign body & 3 & Crohn's disease & .. \\
\hline Blood dyscrasia & 2 & Megacolon & . \\
\hline Intestinal obstruction & .. & Sonnei dysentery & . \\
\hline Threadworm infestation & .. & Pneumonia & . \\
\hline Primary peritonitis . & $\cdots$ & Abdominal pain & . \\
\hline
\end{tabular}

In each instance a mesenteric gland was removed and clotted blood obtained. A second sample of blood was taken after 10 days. Unfortunately samples of faeces were obtained from only a few of the cases and from none of the controls.

All media used in this investigation were prepared as described elsewhere (Bell, 1962). The monolayer tissue cultures used throughout the investigation were human embryo kidney, human embryo liver, human amnion, and two lines of HeLa cells (Bell et al., 1960 ; Bel, 1962).

For attempted isolation of a virus from the lymph nodes the following procedure was used. After excision the node was placed in tissue-culture-maintenance medium and kept warm (room temperature) until delivered to the virus laboratory. There it was dissected into 1-c.mm. fragments and embedded in a fowl plasma clot as used by Rowe et al. (1953) when they first recovered adenovirus from tonsils and adenoids. The clot was covered with growth medium containing $20 \%$ calf serum and incubated at $34-35^{\circ} \mathrm{C}$. in stationary angled racks. In most cases cells grew out from the fragments in a few days and gave a good cell sheet which sometimes degenerated in a similar way to a cell culture infected with adenovirus. At this stage the tubes were frozen overnight at $-20^{\circ} \mathrm{C}$., thawed out to room temperature, and then alternately frozen to $-70^{\circ} \mathrm{C}$. and thawed to room temperature six times to release any intracellular virus. Cultures which did not grow or which gave non-specific degeneration were treated in the same manner. The resulting fluid from these explant cultures was then inoculated into roller tube cultures of at least three of the cell types in use, and incubated at $37^{\circ} \mathrm{C}$. If degeneration was not seen in two to three weeks the tubes were frozen overnight and passed to fresh cultures. At least three blind passages were made for each specimen before discarding as negative.

Specimens of faeces and appendix were homogenized to give a $10-20 \%$ suspension in tissue-culturemaintenance medium and then treated in the same way as explant tissue fluid.

All viruses isolated were identified by neutralization with specific rabbit antisera, and sera were tested for neutralizing and adenovirus complement-fixing antibody (Bell et al., 1960 ; Bell, 1962). The adenovirus antigen used for complement-fixation tests throughout the study was prepared from suspensions of adenovirus types 1, 3, 4,7 , and 14 grown in human-embryo-kidney cells. 